The original publication is available at

www.springerlink.com

Shahab, L., Sarkar, B.K., West, R. (2013). The acute effects of yogic breathing exercises on craving and withdrawal symptoms in abstaining smokers. Psychopharmacology, 225, 875-882 


\title{
The acute effects of yogic breathing exercises on craving and withdrawal symptoms in abstaining smokers
}

\author{
Lion Shahab, Bidyut K. Sarkar and Robert West \\ Department of Epidemiology and Public Health, University College London, London, UK
}

Communicating author:

Lion Shahab, PhD, CPsychol

Department of Epidemiology and Public Health, University College London, 1-19 Torrington

Place, London, WC1E 6BT, UK, Tel: 0207679 1805, Fax: 0207679 8354, Email:

lion.shahab@ucl.ac.uk

Number of pages (excluding title page, abstract, references, tables and figures): 11

We are grateful to Cancer Research UK for funding the study and the support of the UK Centre for Tobacco Control Studies and the Wellcome Trust. RW undertakes consultancy and research for and receives travel funds and hospitality from manufacturers of medications for smoking cessation. He also undertakes training for smoking cessation advisors and has a share of a patent for a novel nicotine delivery device. LS has received honoraria for talk and travel expenses from manufacturers of medications for smoking cessation to attend meetings and workshops. BKS has a UKC-Wellcome trust capacity building grant to PHFI, India and has no conflict of interest to declare. 


\section{ABSTRACT}

Rationale: Breathing exercises have been proposed as a way of combating cigarette cravings, potentially presenting a low-cost, easily scalable smoking cessation aid.

Objective: To evaluate the acute impact of breathing exercises based on yogic 'pranayama' on cravings in abstaining smokers.

Methods: Participants visited the laboratory on two occasions 24 hours apart and were asked to abstain from smoking12 hours prior to the first visit until the end of the second visit. Smokers (N=96) were randomly allocated to a yogic breathing exercise (YBG) or video control (VCG) group. The former was instructed in breathing exercises, practised these for 10 minutes and asked to use these when experiencing cravings until the next visit. The latter was shown a breathing exercise video for 10 minutes and asked to concentrate on their breathing. Strength of urges to smoke, other craving measures and mood and physical symptoms associated with cigarette withdrawal were assessed at the beginning and end of the first visit and again at the second visit.

Results: At immediate follow-up, in the laboratory all craving measures were reduced in YBG compared with VCG (strength of urges: $F(1,96)=16.1, \mathrm{p}<0.001$; cigarette craving: $\mathrm{F}(1,96)=11.3, \mathrm{p}=0.001$; desire to smoke: $\mathrm{F}(1,96)=6.6, \mathrm{p}=0.012)$. There was no effect on mood or physical symptoms. Adherence to the breathing exercise regimen in the following 24 hours was low and at $24 \mathrm{~h}$ follow-up there was no evidence of reduced cravings in YBG compared with VCG.

Conclusions: Simple yogic-style breathing exercises can reduce cigarette craving acutely in the laboratory. Further research is needed to determine how far this translates into field settings.

Key words: yogic breathing, withdrawal symptoms, craving, smoking cessation intervention 


\section{INTRODUCTION}

Although much progress has been made in tobacco control to reduce the global burden of tobacco use in the Western world, prevalence rates in many low and middle income countries such as India have remained high or even continued to rise (Shafey et al. 2009). Owing to the limited resources available in these countries to help smokers stop, there is an urgent need to identify cost-effective and affordable forms of support that can be made available across the whole population. One potential intervention component is brief training on yogic breathing.

Carrying out simple breathing exercises may acutely reduce cigarette craving through a number of mechanisms. First, distraction and focusing attention on breathing as well as on the physical sensation associated with inhalation and exhalation which partially mimics cigarette smoking may reduce the severity or frequency of urges to smoke. Second, breathing may help to relax smokers and thus counteract common withdrawal symptoms. For instance, acute alterations in sympathovagal activity and blunted vagal reactivity are linked to cessation (Ashare et al. 2012), and drugs inhibiting sympathetic activity have been shown to decrease withdrawal symptoms (Sofuoglu et al. 2003). It has been hypothesized that voluntary slow deep breathing functionally resets the autonomic nervous system through stretch induced inhibitory signals and hyperpolarization currents in both neural and nonneural tissue which synchronizes neural elements in the heart, lungs, limbic system and cortex (Jerath et al. 2006). Insofar as slow breathing decreases sympathetic tone (Raupach et al. 2008), this could be one way in which withdrawal symptoms may be alleviated. Third, hyperactivity in the insula, normally associated with hypoxia and a need to breathe, has been implicated in cigarette craving, reflecting the association of deep inhalation with smoking (Kenny 2011;Schrand 2010). Lesions in this area appear to be associated with spontaneous 
quitting (Naqvi et al. 2007). Thus breathing exercises may reduce craving via actions in the insular cortex.

There is a tradition in a number of cultures of using breathing exercises as a means of mind and body control. What little research exists on breathing exercises has yielded promising results. McClernon et al ( 2004) found that controlled deep breathing (taking a series of deep breaths every 30 minutes) significantly reduced withdrawal symptoms, including craving for cigarettes and negative affect (being tense, irritable), while resulting in the maintenance of baseline arousal levels (being wide awake, able to concentrate). The use of body scanning, a relaxation technique encompassing yoga that teaches mindfulness of one's body and breathing (Al-Chalabi et al. 2008), has also been investigated. In two studies, participants followed an audio guide which instructed participants to focus on their breathing by concentrating attention on the abdominal area which resulted in acute reductions in cravings and tobacco withdrawal symptoms (Cropley et al. 2007;Ussher et al. 2009).

Indeed, yoga - a philosophical and cultural system of physical and mental practice that seeks to achieve a very high level of control - has been suggested as complementary treatment for smoking cessation (Bock et al. 2010). Kochupillai and colleagues ( 2005) investigated Sudarshan Kriya and Pranayam, two yogic breathing exercises using rhythmic, cyclical or slow and alternate fast inhalation and exhalation which are taught over a 6 day period and involve mediation as well as chanting. They observed a positive impact of these yogic breathing exercises on tobacco abstinence and found 12 month abstinence rates of the yoga breathing exercises group to be similar to the pharmacological agent, bupropion. 
Although the above studies are suggestive of a benefit, the techniques that have been tested tend to be rather involved (Kochupillai et al. 2005), did not focus on active breathing exercises (Cropley et al. 2007;Ussher et al. 2009) and studies have been limited by inadequate control conditions and short follow-up periods (McClernon et al. 2004). Thus there is a need to establish with confidence whether simple yogic-style breathing exercises could provide a useful aid to cessation. More specifically, it is important to assess whether yogic breathing exercises reduce craving acutely as well as over longer periods as this is the one withdrawal symptom that is most clearly linked to relapse (Hughes et al. 1994;Killen and Fortmann 1997;Shiffman et al. 1997;West et al. 1989). It is also of interest to determine whether yogic breathing exercises might reduce other withdrawal symptoms such as depressed mood, increased appetite and difficulty concentrating (Hughes 1992;Hughes and Hatsukami 1986; West et al. 1987). There is not as strong a rationale for such a reduction and so such analyses would be considered speculative and exploratory. In addition, there is a need to establish whether yogic breathing exercises are considered an acceptable tool by potential users of this technique.

This paper therefore set out to answer the following research question: 1) Do simple yogicstyle breathing exercises have an acute effect in reducing cigarette craving in abstaining smokers? The following secondary research questions were also considered: 2) Does practising such exercises over 24 hours lead to a reduction in cigarette craving over this period?, 3) Do these exercise reduce withdrawal symptoms measured by the Mood and Physical Symptoms Scale (MPSS) either acutely or during 24 hours abstinence?, and 4) How acceptable do smokers find practising these exercises? 


\section{METHODS}

\section{Study design and procedure}

This experimental study had two stages. Following 12 hours' carbon-monoxide (CO) verified abstinence (cut-off $<10 \mathrm{ppm}$ ), participants visited the laboratory to provide consent and complete a baseline questionnaire. Participants were then individually computer randomised to one of two conditions: 1) practising yogic breathing exercises for 10 minutes with the help of a trainer (yogic breathing group, YBG) or 2) watching a video about yogic breathing for 10 minutes (video control group, VCG). In YBG, one researcher trained in yogic breathing instructed all participants in two beginner-level breathing exercises (see Table 1) that were chosen due to their simplicity and ease of implementation, allowing them to be practised relatively inconspicuously by comparison with other techniques. These rhythmic breathing exercises are based on yogic "pranayama" recommended by Yoga Guru Swami Ramdev (Ramdev 2010) for use by the general population. After being instructed, participants practised these exercises for five minutes each and where necessary were given further instructions. In order to control for contact time and expectancy effects, participants in VCG were told that this was a qualitative study of yogic breathing and asked to watch a video of these exercises and to provide their views on yogic breathing. Participants in VCG were not encouraged to practise these exercises.

(Table 1 about here)

Immediately after the intervention, all participants completed a follow-up questionnaire. Participants in the YBG were instructed to continue using the yogic breathing exercises to the extent that they felt it was comfortable and feasible to do so whenever they experienced cigarette cravings and those in the VCG were simply asked to concentrate on their breathing 
when they experience cravings between laboratory visits. All participants were asked to remain abstinent until the next visit, 24 hours later. At the beginning of the second visit, abstinence was CO-verified (cut-off $<10 \mathrm{ppm}$ ) and participants then completed a $24 \mathrm{~h}$ followup questionnaire and were reimbursed $£ 40$ for their time. This study received ethical approval from the UCL ethics committee (Ref 3051/001).

\section{Participants}

Smokers were recruited through advertisements in local newspapers. Participants had to be adult (18+), regular smokers for at least a year (5+ cigarettes/day); be in good health and not pregnant or current users of NRT products. Participants who were not abstinent according to the $\mathrm{CO}$ reading at baseline or follow-up were excluded and replaced $(\mathrm{N}=3)$. Overall, 96 participants (48 per group) were included in the study. Power analysis indicated that this sample was sufficient to detect medium-to-large effects in primary and secondary analyses $(f=0.20-0.30)$ with a power of $80 \%$ at a standard Type I error rate $(\alpha=0.05)$, using a repeated measures design (Faul et al. 2007). Table 2 provides an overview of participant characteristics.

\section{Measures}

At baseline, standard demographic (age, gender, education, ethnicity) and smoking characteristics (cigarette consumption, nicotine dependence using the Fagerstrom Test for Cigarette Dependence (FTCD, Fagerstrom 2012) length of time of smoking, recent quit attempts) were assessed.

The main craving measure 'strength of urges to smoke' (either 'now' or 'today') was assessed by means of a valid and reliable single-item six-point rating scale ranging from 'no 
urges' to 'extremely strong urges' (Fidler et al. 2011;West and Ussher 2010). Additional measures of craving and withdrawal symptoms were derived from reliable and valid rating scales, the Mood and Physical Symptoms Scale, MPSS (West et al. 2006;West and Hajek 2004) and the Shiffman-Jarvik scale (Shiffman and Jarvik 1976), which have been previously used in this form (McEwen et al. 2008;Shahab et al. 2011). Specifically, 'time spent with urges to smoke today' was scored on a 6-point rating scale (ranging from 'not at all' to 'all the time'), 'craving for a cigarette now' on a four-point ratings scale (ranging from 'not at all' to 'extremely') and 'desire for a cigarette now' on a ten-point rating scale (ranging from 'not at all' to 'extremely'). Other withdrawal symptoms were determined with five single-item five-point ratings of depressed mood, irritability, restlessness, hunger and poor concentration (ranging from 'not at all' to 'extremely').

Craving experienced 'today' and 'now' and other withdrawal symptoms were assessed at baseline and 24 hour follow-up and craving experienced 'now' and withdrawal symptoms at immediate follow-up. In addition, at immediate follow-up all participants were asked whether they thought that yogic breathing exercises could be helpful for smokers wanting to stop on a single item five-point scale ranging from 'definitely not' to 'definitely'. At 24 hour followup, all participants were asked whether they had used the yogic breathing exercises, and if so how often, in order to determine adherence in the YBG and check for confounding in VCG. Depending on their group allocation, participants also rated the usefulness of the yogic breathing exercises or concentrating on breathing on a five-point scale ranging from 'not at all' to 'extremely'. 
The primary outcome measure was change in 'strength of urges now' from baseline to immediately after the yogic breathing exercise and change in 'strength of urges today' from baseline to 24 hour follow-up.

\section{Analysis}

Data analysis was carried out in SPSS 16. Baseline group differences were assessed by independent t-tests and $\mathrm{X}^{2}$-test for continuous and categorical variables, respectively. Given the mixed design of this study, within subjects and between group differences were tested with general linear mixed models (e.g. West 2009). Group allocation and time of assessment were specified as fixed factors in the model and effects tested using the maximum likelihood technique. Statistical significance was set at a standard level $(\alpha=0.05)$ and adjusted in posthoc analysis for multiple comparison using the Sidak correction. 


\section{RESULTS}

The sample was relatively young, well-educated and ethnically diverse (Table 2). The average FTCD score indicated low cigarette dependence; craving and withdrawal symptoms were moderate at baseline following 12 hours of CO-verified abstinence. Characteristics were equally balanced across groups.

(Table 2 about here)

Immediately following the intervention there was a significant reduction in all craving measures in the yogic breathing group compared with the control group (Figure 1). A significant group by time interaction for the primary outcome measure indicated that the reduction in 'strength of urges to smoke now' was significantly greater in YBG than VCG at immediate follow-up $(\mathrm{F}(1,96)=16.1, \mathrm{p}<0.001)$. This was also the case for the two other craving measures 'craving a cigarette now' $(F(1,96)=16.1, p<0.001)$ and 'desire to smoke now' $(F(1,96)=6.6, p=0.012)$. There was no effect of yogic breathing as compared with the video control for withdrawal symptoms; both groups showed reductions in these symptoms (Table 3).

(Fig.1 about here)

At $24 \mathrm{~h}$ follow, there were no significant group by time interactions for any of the craving or withdrawal symptom measures with the exception of 'feeling hungry' (Table 3 ). Participants in YBG reported marginally greater reductions in feeling hungry than those in VCG $(\mathrm{F}(1,96)=4.5, \mathrm{p}=0.04)$. 
(Table 3 about here)

Fidelity to the treatment protocol at follow up was low; only a third (35.4\%, 95\%CI 21.948.9) in YBG had practised yogic breathing 'often' or 'very often'. On average, YBG participants had used the exercises 7.7 times (95\%CI 3.1-12.4) outside the laboratory but frequency of practise was not associated with the time spent with urges to smoke over the last 24 hours $(\mathrm{R}=0.16, \mathrm{p}=0.277)$. Surprisingly, 37.5\% (95\%CI 23.8-51.2) of participants in VCG also reported having practised yogic breathing at least once since the last visit. While $10.4 \%$ (95\%CI 3.5-22.7) in VCG reported having practised yogic breathing 'often' or 'very often', this was significantly lower than in $\mathrm{YBG}\left(\mathrm{X}^{2}(1)=8.5, \mathrm{p}=0.004\right)$. Restricting the sample in a post-hoc analysis to those in the YBG who had practised yogic breathing 'often' or 'very often' and those who had not practised it in VCG resulted in a significant group by time interaction for 'craving a cigarette now' $(F(1,46)=4.0, p=0.048)$, this was reduced in YBG compared with VCG at 24h follow-up.

(Fig.2 about here)

Immediately after watching or practising yogic breathing exercises, the majority of participants thought that yogic breathing was 'probably' or 'definitely' helpful for smokers wanting to stop smoking $(70.8 \%, 95 \% \mathrm{CI} 61.7-79.9)$ and that they would 'probably' or 'definitely' use it in a future quit attempt (72.9\%, 95\%CI 64.0-81.8). There were no differences by group (Figure 2). At 24 hour follow up, a higher proportion of participants in YBG rated yogic breathing exercises to have been 'very much' or 'extremely' useful (47.9\%, 95\%CI 33.8-62.0) than participants in the VCG group appraised concentrating on breathing to be $\left(18.8 \%, 95 \% \mathrm{CI} 7.7-29.8 ; \mathrm{X}^{2}(1)=9.2, \mathrm{p}=0.002\right)$. 


\section{DISCUSSION}

Yogic breathing exercise reduced cravings acutely among abstaining smokers. The effect was not observed with other withdrawal symptoms. Instruction to practise these breathing exercises for 24 hours did not result in a detectable reduction in craving during the period, but adherence to the instruction was low.

The present study confirms the results of previous studies of either generic (Cropley et al. 2007;McClernon et al. 2004;Ussher et al. 2009) or complex yogic (Kochupillai et al. 2005) breathing exercises finding that simple yogic breathing exercises can acutely reduce cigarette cravings It extends previous findings to show that this effect may not easily translate outside the laboratory. Moreover, the fact that yogic breathing exercises affected measures of cravings but not other withdrawal symptoms suggests a specific effect of this type of exercise rather than a generalised distraction or expectancy effect.

The failure to detect an effect of the breathing exercises during 24 hours of abstinence may have been due to low adherence as suggested by the finding that there was a significant reduction in cravings at follow-up only among those who had practised exercises. As the current sample was inexperienced in the use of such breathing exercises and arguably relatively naïve to yoga, this kind of approach may be more effective in culturally attuned populations such as in India where yoga enjoys more widespread familiarity and acceptance. However, no specific behaviour change techniques were used to maximise adherence and it could be that this problem is readily addressed by, for example, setting a target for a minimum number of times to practice the exercises in a day. It is also possible that the particular exercises concerned were not easily practised in all situations. For example, some participants may have found the alternative nostril breathing embarrassing to practise in 
public or abdominal breathing difficult to implement in company. Lastly, the presence of smoking cues outside the laboratory may have resulted in stronger cravings and the intervention may have been practised in generally more stressful and challenging situations, resistant to the effect of the breathing exercise, thus reducing its impact.

Notwithstanding low fidelity, yogic breathing exercises were generally rated as acceptable and useful for smokers wanting to stop, indicating that in theory these simple exercises could be incorporated into existing interventions.

Whilst it is unclear whether the effect of yogic breathing can be translated into longer lasting outcomes, the findings are encouraging in terms of a smoking cessation as craving for cigarettes is among the most commonly reported withdrawal symptoms and a strong predictor of relapse (Hughes et al. 1994;Killen and Fortmann 1997;Shiffman et al. 1997; West et al. 1989).

The study had a number of limitations. Although abstinence was verified biochemically, initial smoking status was verified only verbally. However, as advertising was targeted at smokers, we believe it is unlikely that non-smokers were included as also evidenced by slightly elevated $\mathrm{CO}$ readings at baseline. Nonetheless, participants may not be representative of more addicted smokers given their relatively low nicotine dependence and only moderate craving and withdrawal symptoms and as participants were not trying to quit, it may be that cravings would be different in those seeking to remain abstinent. Yet, there is no reason to expect that this would differentially affect response to breathing exercises. Only having 24 hours of abstinence in the field test may have limited the opportunity to detect an effect of the breathing exercises, but other studies using a similar time window have picked up effects of 
interventions as diverse as nicotine replacement therapy, exercise and glucose tablets (Shahab et al. 2011;Ussher et al. 2001;e.g. West et al. 1990). In addition, the study was very tightly controlled and some participants in the control group practised the exercises as well which may have made it difficult to pick up an effect. Only one person was used to train the breathing exercises and it may be that different results would be obtained with different trainers. However, they did operate to a detailed script. Finally, this study used two different forms of breathing exercise. We are not able to say which of these in particular was effective or whether other exercise might be equally, or more effective.

In conclusion, this study showed that yogic-style breathing exercises can reduce cravings for cigarettes acutely in the laboratory, but we were unable to demonstrate an effect when practised over 24 hours of abstinence. Further research is needed to determine whether such exercises can be effective in the field and therefore benefit smokers wanting to stop.

\section{Acknowledgements}

We are grateful to Cancer Research UK for funding the study and the support of the UK Centre for Tobacco Control Studies and the Wellcome Trust. We would also like to thank Sharlene Andrew, Antonia Shahab and Ndidi Superville for their help with carrying out this study. 


\section{REFERENCES}

\section{Reference List}

Al-Chalabi L, Prasad N, Steed L, Stenner S, Aveyard P, Beach J, Ussher M (2008) A pilot randomised controlled trial of the feasibility of using body scan and isometric exercises for reducing urge to smoke in a smoking cessation clinic. BMC Public Health 8:349

Ashare RL, Sinha R, Lampert R, Weinberger AH, Anderson GM, Lavery ME, Yanagisawa K, McKee SA (2012) Blunted vagal reactivity predicts stress-precipitated tobacco smoking. Psychopharmacology (Berl) 220:259-268

Bock BC, Morrow KM, Becker BM, Williams DM, Tremont G, Gaskins RB, Jennings E, Fava J, Marcus BH (2010) Yoga as a complementary treatment for smoking cessation: rationale, study design and participant characteristics of the Quitting-in-Balance study. BMC Complement Altern Med 10:14

Cropley M, Ussher M, Charitou E (2007) Acute effects of a guided relaxation routine (body scan) on tobacco withdrawal symptoms and cravings in abstinent smokers. Addiction 102:989-993

Fagerstrom K (2012) Determinants of tobacco use and renaming the FTND to the Fagerstrom Test for Cigarette Dependence. Nicotine Tob Res 14:75-78

Faul F, Erdfelder E, Lang AG, Buchner A (2007) G*Power 3: a flexible statistical power analysis program for the social, behavioral, and biomedical sciences. Behav Res Methods 39:175-191

Fidler JA, Shahab L, West R (2011) Strength of urges to smoke as a measure of severity of cigarette dependence: comparison with the Fagerstrom Test for Nicotine Dependence and its components. Addiction 106:631-638

Hughes JR (1992) Tobacco withdrawal in self-quitters. J Consult Clin Psychol 60:689-697

Hughes JR, Hatsukami D (1986) Signs and Symptoms of Tobacco Withdrawal. Archives of General Psychiatry 43:289-294

Hughes JR, Higgins ST, Bickel WK (1994) Nicotine withdrawal versus other drug withdrawal syndromes: similarities and dissimilarities. Addiction 89:1461-1470

Jerath R, Edry JW, Barnes VA, Jerath V (2006) Physiology of long pranayamic breathing: neural respiratory elements may provide a mechanism that explains how slow deep breathing shifts the autonomic nervous system. Med Hypotheses 67:566-571

Kenny PJ (2011) Tobacco dependence, the insular cortex and the hypocretin connection. Pharmacol Biochem Behav 97:700-707

Killen JD, Fortmann SP (1997) Craving is associated with smoking relapse: findings from three prospective studies. Exp Clin Psychopharmacol 5:137-142 
Kochupillai V, Kumar P, Singh D, Aggarwal D, Bhardwaj N, Bhutani M, Das SN (2005) Effect of rhythmic breathing (Sudarshan Kriya and Pranayam) on immune functions and tobacco addiction. Ann N Y Acad Sci 1056:242-252

McClernon FJ, Westman EC, Rose JE (2004) The effects of controlled deep breathing on smoking withdrawal symptoms in dependent smokers. Addict Behav 29:765-772

McEwen A, West R, Gaiger M (2008) Nicotine absorption from seven current nicotine replacement products and a new wide-bore nicotine delivery device. Journal of Smoking Cessation 3:117-123

Naqvi NH, Rudrauf D, Damasio H, Bechara A (2007) Damage to the insula disrupts addiction to cigarette smoking. Science 315:531-534

Ramdev S (2010) Yog Science: Pranayam / Yog Aasan (DVD Part 1). Patanjali Yog Vidyapeeth, Haridwar, India,

Raupach T, Bahr F, Herrmann P, Luethje L, Heusser K, Hasenfuss G, Bernardi L, Andreas S (2008) Slow breathing reduces sympathoexcitation in COPD. Eur Respir J 32:387-392

Schrand JR (2010) Does insular stroke disrupt the self-medication effects of nicotine? Med Hypotheses 75:302-304

Shafey O, Eriksen M, Ross H, Mackay J (2009) The Tobacco Atlas. American Cancer Society, Atlanta

Shahab L, McEwen A, West R (2011) Acceptability and effectiveness for withdrawal symptom relief of a novel oral nicotine delivery device: a randomised crossover trial. Psychopharmacology (Berl) 216:187-196

Shiffman S, Engberg JB, Paty JA, Perz WG, Gnys M, Kassel JD, Hickcox M (1997) A day at a time: predicting smoking lapse from daily urge. J Abnorm Psychol 106:104-116

Shiffman SM, Jarvik ME (1976) Smoking withdrawal symptoms in two weeks of abstinence. Psychopharmacology (Berl) 50:35-39

Sofuoglu M, Babb D, Hatsukami DK (2003) Labetalol treatment enhances the attenuation of tobacco withdrawal symptoms by nicotine in abstinent smokers. Nicotine Tob Res 5:947-953

Ussher M, Cropley M, Playle S, Mohidin R, West R (2009) Effect of isometric exercise and body scanning on cigarette cravings and withdrawal symptoms. Addiction 104:1251-1257

Ussher M, Nunziata P, Cropley M, West R (2001) Effect of a short bout of exercise on tobacco withdrawal symptoms and desire to smoke. Psychopharmacology (Berl) 158:66-72

West BT (2009) Analyzing longitudinal data with the linear mixed models procedure in SPSS. Eval Health Prof 32:207-228

West R, Hajek P (2004) Evaluation of the mood and physical symptoms scale (MPSS) to assess cigarette withdrawal. Psychopharmacology 177:195-199 
West R, Hajek P, Burrows S (1990) Effect of glucose tablets on craving for cigarettes. Psychopharmacology (Berl) 101:555-559

West R, Ussher M (2010) Is the ten-item Questionnaire of Smoking Urges (QSU-brief) more sensitive to abstinence than shorter craving measures? Psychopharmacology (Berl) 208:427432

West R, Ussher M, Evans M, Rashid M (2006) Assessing DSM-IV nicotine withdrawal symptoms: a comparison and evaluation of five different scales. Psychopharmacology (Berl) 184:619-627

West RJ, Hajek P, Belcher M (1987) Time course of cigarette withdrawal symptoms during four weeks of treatment with nicotine chewing gum. Addict Behav 12:199-203

West RJ, Hajek P, Belcher M (1989) Severity of withdrawal symptoms as a predictor of outcome of an attempt to quit smoking. Psychol Med 19:981-985 


\section{TABLES AND FIGURES}

\section{Tables}

\begin{tabular}{|c|c|}
\hline Three part breath (Pranayama) & $\begin{array}{l}\text { Alternate nostril inhalation- } \\
\text { exhalation (Anulom-Vilom) }\end{array}$ \\
\hline $\begin{array}{l}\text { - Sit with your back straight in a stable and relaxed } \\
\text { position } \\
\text { - Begin for about } 10 \text { seconds by simply concentrating on } \\
\text { the natural inhalations and exhalations of your breath } \\
\text { without changing anything } \\
\text { - Then start to inhale deeply through your nose } \\
\text { - On each inhalation, breathe deeply using your } \\
\text { abdomen. It should feel like you are expanding your } \\
\text { belly with air like a balloon } \\
\text { - On each exhalation, pull your belly button back towards } \\
\text { your spine and use your belly to exhale air through your } \\
\text { nose } \\
\text { - Repeat this for five breaths } \\
\text { - Then 'fill your belly' with air as before. Then draw in a } \\
\text { little more air and let it expand your rib cage so that you } \\
\text { feel sides of your chest go out } \\
\text { - Then exhale, letting the air go first from your rib cage } \\
\text { letting the ribs slide closer together and then expel the } \\
\text { air from your belly drawing in your navel as before } \\
\text { - Repeat this deep breathing into the belly and rib cage } \\
\text { for five breaths } \\
\text { - Then do as before and draw air into the belly and the } \\
\text { rib cage. Then breathe in a little bit more to allow air to } \\
\text { fill the upper chest and collarbone region until it } \\
\text { expands and rises } \\
\text { - Then exhale, letting the air go first from the collarbone } \\
\text { and upper chest region, allowing them to sink back } \\
\text { down, followed by the rib cage and then the belly } \\
\text { - Repeat the three-part breath for ten breaths }\end{array}$ & $\begin{array}{l}\text { - Sit in a comfortable position } \\
\text { with the back straight and } \\
\text { upright } \\
\text { - Fold the fore and middle } \\
\text { fingers of your hand into the } \\
\text { palm and position your hand on } \\
\text { the bridge of your nose to } \\
\text { enable use of your thumb and } \\
\text { the ring finger to close the } \\
\text { nostrils alternatively. } \\
\text { - Close the right nostril with the } \\
\text { thumb of your right hand and } \\
\text { breathe in deeply inhaling } \\
\text { through the left nostril, then } \\
\text { close the left nostril with your } \\
\text { ring finger and release the } \\
\text { thumb from the right nostril and } \\
\text { now exhale through the right } \\
\text { nostril } \\
\text { - Then inhale through the right } \\
\text { nostril, close the right nostril } \\
\text { and exhale through the left } \\
\text { nostril } \\
\text { - Now inhale through the left } \\
\text { nostril, close the left nostril and } \\
\text { exhale through right nostril. }\end{array}$ \\
\hline
\end{tabular}

Table 1 Instructions for yogic breathing exercise 


\begin{tabular}{|c|c|c|c|}
\hline & All $(\mathrm{N}=96)$ & $\begin{array}{c}\mathrm{YBG} \\
(\mathrm{N}=48)\end{array}$ & $\begin{array}{c}\mathrm{VCG} \\
(\mathrm{N}=48)\end{array}$ \\
\hline \multicolumn{4}{|l|}{ Socio-demographic characteristics } \\
\hline Mean (SD) age & $33.9(10.4)$ & $33.2(10.4)$ & $34.6(10.5)$ \\
\hline Percent $(\mathrm{N})$ male & $54.2 \quad(52)$ & $50.0 \quad(24)$ & $58.3 \quad(28)$ \\
\hline Percent $(\mathrm{N})$ college or above & 67.7 & 60.4 & 75.0 \\
\hline Percent $(N)$ white & 65.6 & 68.8 & 62.5 \\
\hline \multicolumn{4}{|l|}{ Smoking characteristics } \\
\hline Mean (SD) cigarettes per day & $13.1(6.3)$ & $12.6(6.7)$ & $13.5 \quad(5.9)$ \\
\hline Mean (SD) years of smoking & $16.5(10.6)$ & $16.0(10.4)$ & $16.9(10.8)$ \\
\hline Mean (SD) FTCD & $3.8(2.8)$ & $3.4(2.2)$ & $4.3(3.2)$ \\
\hline Percent $(N)$ quit attempt last year & $44.8 \quad(43)$ & $43.8 \quad(21)$ & 45.8 \\
\hline Mean (SD) CO level in ppm & $4.0 \quad(2.4)$ & $4.1 \quad(2.6)$ & (2.1) \\
\hline \multicolumn{4}{|l|}{ Craving characteristics } \\
\hline Mean (SD) strength of urges today ${ }^{1}$ & $2.6(1.1)$ & $2.4(1.1)$ & $(1.1)$ \\
\hline Mean (SD) time spent with urges today ${ }^{1}$ & $2.5(1.3)$ & $2.2(1.0)$ & (1.4) \\
\hline Mean (SD) strength of urges now ${ }^{1}$ & $2.2(1.4)$ & $2.1 \quad(1.3)$ & (1.5) \\
\hline Mean (SD) craving a cigarette now ${ }^{2}$ & $1.9(1.1)$ & $1.8(1.0)$ & $(1.2)$ \\
\hline Mean (SD) desire to smoke now ${ }^{3}$ & $4.9(2.4)$ & $4.7(2.4)$ & $5.2(2.5)$ \\
\hline \multicolumn{4}{|l|}{ Withdrawal symptom characteristics ${ }^{4}$} \\
\hline Mean (SD) feeling depressed & $1.5(0.8)$ & $1.5(0.8)$ & $(0.8)$ \\
\hline Mean (SD) feeling anxious & $2.1 \quad(1.1)$ & (1.1) & (1.2) \\
\hline Mean (SD) feeling irritable & $2.3(1.1)$ & $2.3(1.2)$ & (1.0) \\
\hline Mean (SD) feeling restless & $2.5(1.3)$ & $2.5(1.2)$ & (1.3) \\
\hline Mean (SD) feeling hungry & $2.7 \quad(1.6)$ & $2.8(1.8)$ & (1.4) \\
\hline Mean (SD) poor concentration & $2.5(2.4)$ & $2.2(1.3)$ & $2.8(3.1)$ \\
\hline
\end{tabular}

Table 2 Baseline sample characteristics; YBG: Yogic breathing Group; VCG: Video control group; NRT: Nicotine replacement therapy; FTCD: Fagerström test of cigarette dependence; CO: Carbon-monoxide; ppm: parts per million; ${ }^{1}$ On scale ranging from $0-5,{ }^{2}$ On scale ranging from $0-4 ;{ }^{3}$ On scale ranging from $1-10 ;{ }^{4}$ On scale ranging from $1-5$

\begin{tabular}{|c|c|c|c|}
\hline \multirow{2}{*}{$\begin{array}{l}\text { Withdrawal } \\
\text { symptoms }\end{array}$} & \multicolumn{2}{|c|}{ Mean (SD) change from baseline $\mathrm{a}^{\mathrm{a}}$} & \multirow{2}{*}{$\mathrm{P}$} \\
\hline & YBG $(\mathrm{N}=48)$ & VCG $(\mathrm{N}=48)$ & \\
\hline \multicolumn{4}{|c|}{ Immediate follow-up } \\
\hline Feel depressed & $-0.291(0.617)^{\star \star}$ & $-0.125(0.570)$ & 0.168 \\
\hline Feel anxious & $-0.625(0.841)^{\star \star * *}$ & $-0.521(0.967)^{\star \star *}$ & 0.571 \\
\hline Feel irritable & $-0.917(0.986)^{\star \star *}$ & $-0.729(0.736)^{\star \star *}$ & 0.289 \\
\hline Feel restless & $-0.792(0.850)^{* * *}$ & $-0.688(0.949)^{* * *}$ & 0.568 \\
\hline Feel hungry & $-0.688(1.703)^{\star *}$ & $-0.188(0.762)$ & 0.064 \\
\hline Poor concentration & $-0.438(0.897)^{* *}$ & $-0.854(3.108)$ & 0.369 \\
\hline \multicolumn{4}{|c|}{$24 \mathrm{~h}$ follow-up } \\
\hline Feel depressed & $-0.042(0.967)$ & $-0.063(0.998)$ & 0.917 \\
\hline Feel anxious & $-0.064(1.292)$ & $-0.104(0.831)$ & 0.855 \\
\hline Feel irritable & $0.042(0.967)$ & $0.063(1.731)$ & 0.952 \\
\hline Feel restless & $0.000(1.989)$ & $-0.125(1.331)$ & 0.715 \\
\hline Feel hungry & $-0.458(1.810)$ & $0.188(1.123)$ & 0.036 \\
\hline Poor concentration & $0.292(2.968)$ & $-0.521(3.142)$ & 0.191 \\
\hline
\end{tabular}

Table 3 Changes in withdrawal symptoms by group and time of assessment; ${ }^{a}$ Raw scores;

Within-group changes significant at $* \mathrm{p}<.05 ; * * \mathrm{p}<.01 ; * * * \mathrm{p}<.001$; Significant interactions in italics; YBG: Yogic breathing group; VCG: Video control group 


\section{Figures}

A
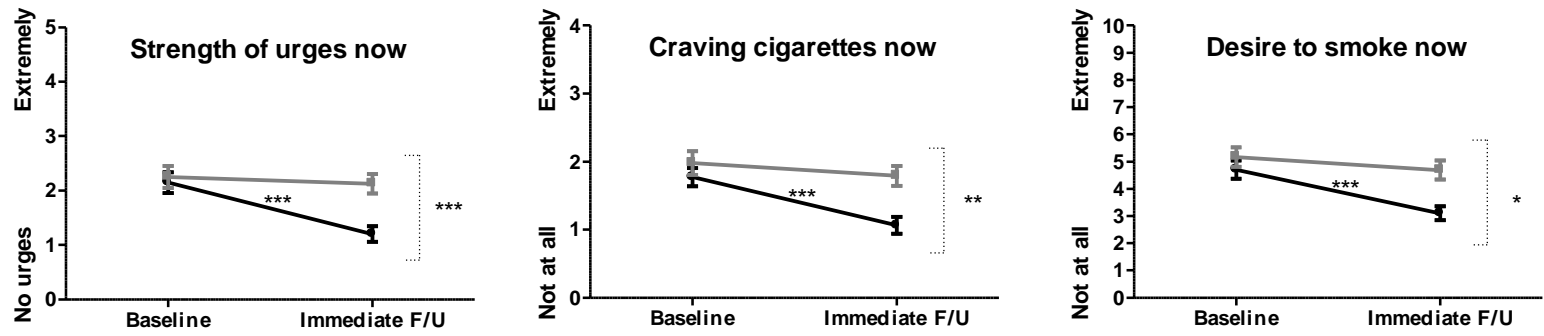

B
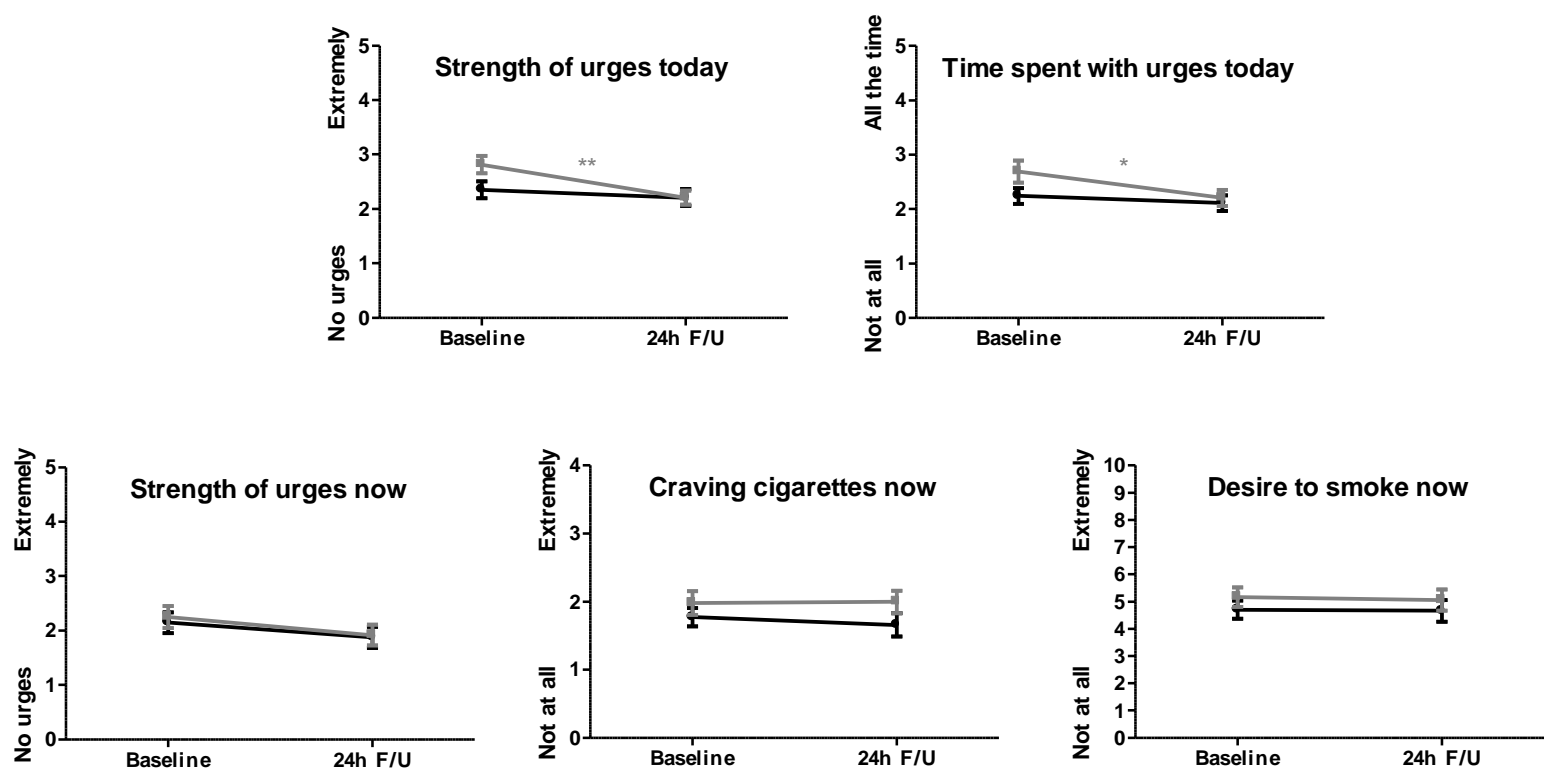

$\rightarrow$ Yogic breathing group $\quad \rightarrow$ Video control group

Fig.1 Changes in cravings at (A) immediate and (B) 24h follow-up by group; Error bars are

SEM; Dashed line indicates significant interaction; ${ }^{*} \mathrm{p}<.05 ; * * \mathrm{p}<.01 ; * * * \mathrm{p}<.001$ 

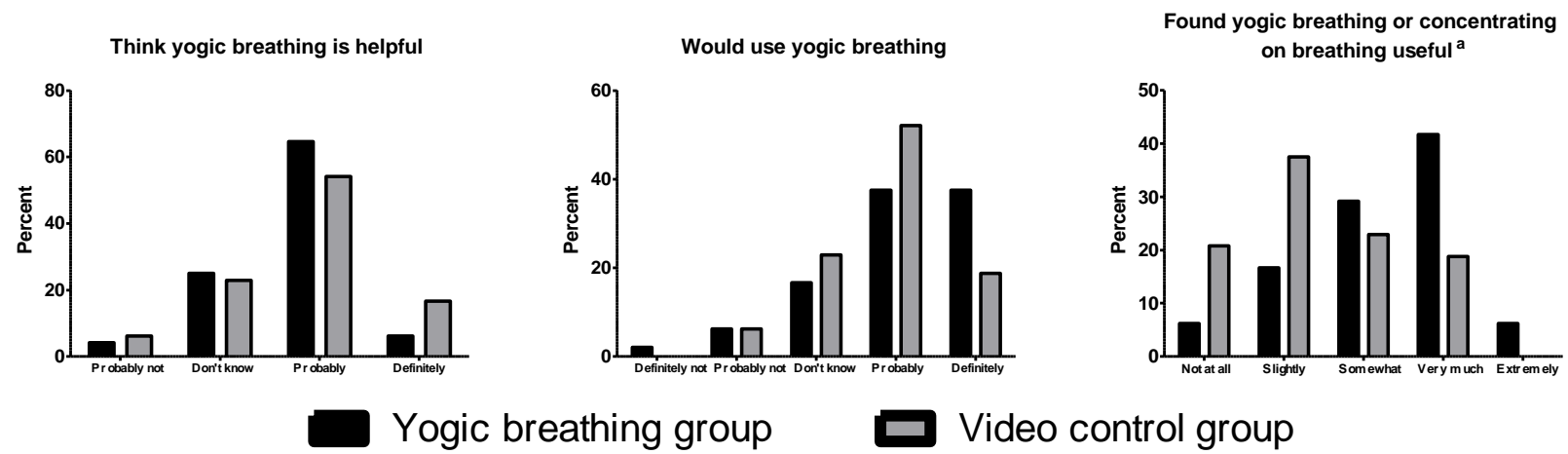

Fig 2 Acceptability of yogic breathing; ${ }^{a}$ Yogic breathing group asked about yogic breathing and video control group about concentrating on breathing 